\title{
Study on Snake Venom Protein-Antibody Interaction by Surface Plasmon Resonance Spectroscopy
}

\author{
Subhankar N. CHOUDHURY ${ }^{1}$, Barlina KONWAR ${ }^{1}$, Simran KAUR ${ }^{2}$, \\ Robin DOLEY ${ }^{2}$, and Biplob MONDAL ${ }^{1 *}$ \\ ${ }^{1}$ Department of Electronics and Communication Engineering, Tezpur University, Tezpur 784028, Assam, India \\ ${ }^{2}$ Deptment of Molecular Biology and Biotechnology, Tezpur University, Tezpur 784028, Assam, India \\ *corresponding author: Biplob MONDAL～Email: biplob.tezu@gmail.com
}

\begin{abstract}
The development of a portable and inexpensive surface plasmon resonance (SPR) measurement device with the integrated biosensor for the detection of snake venom protein is presented in this paper. For the construction of the sensing element, amine coupling chemistry is used to bio-functionalize silver coated glass slide with antibodies like immunoglobulin (IgG). The immobilization of the antibody is confirmed by spectroscopic measurements like ultraviolet-visible spectroscopy (UV-Vis) and Fourier-transforms infrared spectroscopy (FTIR). The device is calibrated with the standard solution of sodium chloride and ethanol before testing venom protein samples. To investigate the bio-molecular interactions, crude venom of Indian cobra (concentration range: $0.1 \mathrm{mg} / \mathrm{ml}-1.0 \mathrm{mg} / \mathrm{ml}$ ) in the phosphate buffer solution (PBS) are exposed to the biosensor. The experimentally measured data indicate the shift in the plasmon resonance angle from its initial value $\left(52^{\circ}\right)$ to $54^{\circ}$ for $0.1 \mathrm{mg} / \mathrm{ml}$ and $60^{\circ}$ for $1.0 \mathrm{mg} / \mathrm{ml}$ protein solution.
\end{abstract}

Keywords: Surface plasmon resonance; biosensor; venom protein

Citation: Subhankar N. CHOUDHURY, Barlina KONWAR, Simran KAUR, Robin DOLEY, and Biplob MONDAL, "Study on Snake Venom Protein-Antibody Interaction by Surface Plasmon Resonance Spectroscopy," Photonic Sensors, 2018, 8(3): 193202.

\section{Introduction}

Optical biosensors have been used extensively in the scientific community for several purposes, most notably to determine the association and dissociation kinetics, protein-protein [1], or nucleic acid hybridization interactions [2], etc. Since the demonstration of utility of surface plasmon resonance (SPR) as the optical biosensor [3], an increasing popularity of the technique is observed in fundamental biological studies, health care research, drug discovery and clinical diagnosis [4], environmental monitoring [5], food safety and security [6], and agricultural research, etc. SPR has been established as a potential tool for the detection of bio-analytes producing extraordinary detection limit and has added a unique advantage of real-time label-free detection of biological species in the molecular level. Several reports are available challenging the detection of pico-mole concentration of small bio-molecules [7, 8]. An optical method is used to measure the change in the refractive index of the medium in close vicinity of a metal surface [9-13]. However, the traditional methods for the excitation of surface plasmon using methods like Kretschmann's [14] and Otto's [15] configurations

Received: 22 March 2018 / Revised: 25 May 2018

(C) The Author(s) 2018. This article is published with open access at Springerlink.com

DOI: $10.1007 / \mathrm{s} 13320-018-0501-1$

Article type: Regular 
involve bulky and complex instrumentations. Worldwide, there are several manufacturers providing SPR systems for academic and industrial research laboratories which differ in their ways of using the technologies and designs. However, a major market share is predominately led by BIAcore $^{\mathrm{TM}}$ Technology with its first commercial instrument introduced in 1991. Other major players of the SPR system include Nicoya lifesciences, BioNavis, Biosensing Instruments, Bio-Rad, Affinite Instruments, Reichert Technologies, and NanoSPR devices. The commercial instruments from these manufacturers provide high performance SPR measurements and have the unique and advanced features but are available at extremely high cost.

Snakebite remains as one of the common health issues encountered in the tropical and sub-tropical part of the world especially among forest workers, snake catchers, farmers, and agriculturists [16]. Despite better understanding of clinical features of envenoming and sufficient production of antivenom for treatment of snake bite victims, there are around 125000 cases of mortality and morbidity annually around the world [17]. In most of the cases, the fatalities are primarily due to the lack of the knowledge, poor medical attention like improper diagnosis, delay in identifying the right type of antivenom or overdose of antivenom. The pathophysiology of snakebite is very complex due to the rich diversity of venom protein families, hence the identification of the snake involved in envenomation is a challenging task. Proper identification of the snake will allow physicians to eventually make fast decisions and administer the victim with the right type of antivenom. Biosensors to detect the presence of the toxin in the body of the patients will ease the diagnosis process for the proper treatment. Hence, the development of an intelligent system with the integrated biosensor that can rapidly diagnose the presence of snake venom in the human blood to provide precise medical care to the victim is the need of the day.
Over the years, various detection tests have been developed with immunological reactions based enzyme linked immunosorbent assay (ELISA) method being the mostly used one for venom protein analysis. However, in recent years, various other techniques such as optical immunoassays (OIA), venom/antibody micro-array assay, and polymerase chain reaction (PCR) based assays are used. Dong and co-workers in 2004 reported the optical immunoassays [18] based on the principle of the detection of physical changes in the thickness of the molecular thin film resulting from specific binding events on an optical silicon chip (SILAS $\left.{ }^{\mathrm{TM}}-\mathrm{I}\right)$. The reflection of white light through the thin film results in destructive interference of a particular wavelength of light from gold to purple-blue depending on the thickness of the thin film formed or amount of venom in the test sample. Malih et al. in 2014 and Brand et al. in 2014 published reports on the interaction of the antitoxin DM43 with a snake venom metalloproteinase analyzed by the mass spectrometry and surface plasmon resonance technique (SPR), respectively [19, 20]. However, these reported methods are affected by the drawbacks like complicated sample preparation, long analysis time, expensive and large instrumentation, and limited dynamic range.

Surface plasmon resonance in such applications can produce extraordinary detection limit because of its capacity to give extremely high sensitivity to small change in the refractive index near the sensor surface. In this paper, we report on the design and fabrication of a surface plasmon resonance biosensor for the detection of snake venom protein using portable instruments in a cost effective way. Unlike conventional systems, the angular interrogation of the SPR is demonstrated without using any mechanically moving element. Also, the use of simple and inexpensive components makes labs with limited budget to custom-made SPR measurement setup for quantitative and first-hand analysis of samples. 


\section{Experimental methods}

\subsection{Chemicals and reagents}

N-hydroxysuccinimide (NHS), 1-ethyl-3 (3-dimethylaminopropyl) carbodiimide (EDC), 11-mercuptoundecanoic acid (11-MUA), ethanol amine (EA), and bovine serum albumin (BAS) are purchased from Sigma-Aldrich. Polyvalent antivenom is procured from VINS Bioproducts (Hyderabad, India). All other chemicals used are of analytical grade and are procured from SigmaAldrich.

\subsection{Venom protein}

The crude venom of Indian cobra (Najanaja) is procured from Irula Snake Catchers Society, Tamil Nadu, India. The venom is dissolved in $20 \mathrm{mM}$ Tris $\mathrm{Cl}$ buffer $\mathrm{pH} 7.4$ at a concentration of $10 \mathrm{mg} / \mathrm{ml}$ for use. The polyvalent antivenom IgG (Batch no. $01 \mathrm{AS} 15007$, expiry date $01 / 2019$ ) is purchased in the form of lyophilized powder from VinsBioproducts limited, Telangana, India. It is then reconstituted in $20 \mathrm{mM}$ Tris $\mathrm{Cl}, \mathrm{pH} 7.4$ and stored at $4{ }^{\circ} \mathrm{C}$ until use. The antivenom used here is raised against four snakes found in India namely, Najanaja, Bungaruscaeruleus, Daboiarusselii, and Echiscarinatus.

\subsection{Sensor fabrication}

Conventionally, silver $(\mathrm{Ag})$ and gold $(\mathrm{Au})$ thin films are considered to be ideal for the excitation of surface plasmon because of their extraordinary properties like the efficiency in resonating conduction band electron at the suitable wavelength, biochemical and thermal stability, inert nature, and amenable to attaching organic molecule on its surface. Contrary to gold, silver is cheap, and the thin film of silver $(50 \mathrm{~nm}-80 \mathrm{~nm}$ thick) is reported to produces the sharpest SPR signal and is more sensitive to the refractive index variation than gold $[21,22]$. Full width half maxima of for gold and silver in air are $10.67^{\circ}$ and $0.71^{\circ}$, respectively [23]. In order to trade-off between the cost and quality, the silver thin film is used for the excitation of surface plasmons. For the preparation of the sensor chip, glass cover slips $(24 \mathrm{~mm} \times 24 \mathrm{~mm} \times 1 \mathrm{~mm})$ are coated with about $50-\mathrm{nm}$ thick thermally deposited silver. Before the thermal deposition process, the glass slides are thoroughly cleaned by ringing in the acetone vapor, methanol, and distilled water. A thin layer of chromium or titanium ( $5 \mathrm{~nm}$ ) deposited prior to the deposition of $\mathrm{Ag}$ improves the adhesion of $\mathrm{Ag}$ with glass.

Amine coupling chemistry [24] is then followed to bio-functionalize the bare silver coated slides with suitable antibodies in the construction of the sensing element of the biosensor. Figure 1(a) shows the scheme used to covalently immobilize antibody on the metal coated surface. In details, the understanding on the various strategies for immobilization of protein work reported by Rusmini et al. may be referred [25]. Thiol-metal interactions are frequently used for covalent binding biomolecules on metal surfaces. The thiol groups demonstrate the strong affinity towards the noble metal surfaces allowing them formation of covalent bonds between the sulphur head group of thiol and silver atoms [26-28].

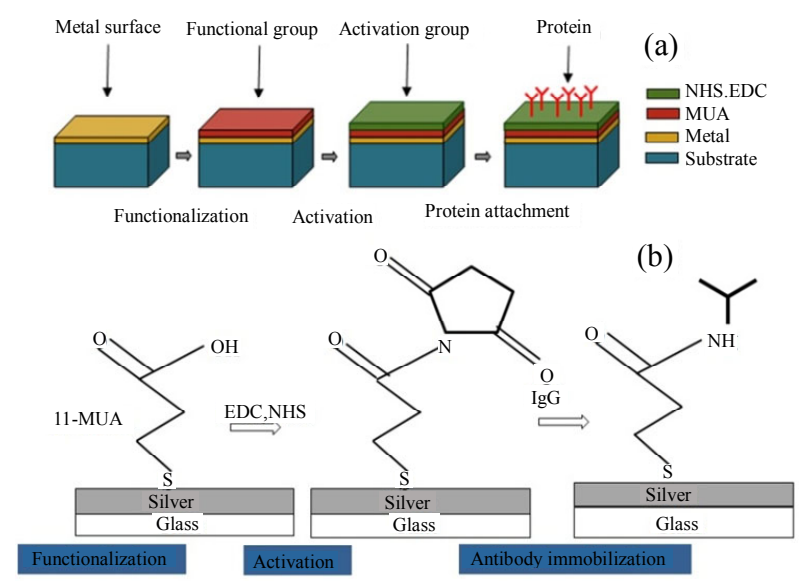

Fig. 1 Protein immobilization scheme: (a) schematic representation and (b) amine coupling method.

Initially, $\mathrm{Ag}$ deposited glass slides are functionalized with a self-assembled monolayer (SAM) of 11 MUA $(2 \mathrm{~nm}-3 \mathrm{~nm})$ by dipping them in $1 \mathrm{mM}$ ethanoic solution of 11-MUA. For $1 \mathrm{mM}$ MUA solution, a constant room temperature dipping 
interval of $24 \mathrm{hrs}$ in a closed container is maintained in order to obtain the proper molecular organization. The MUA coated chip is rinsed with ethanol and dried under nitrogen stream. The sulphur head group of MUA binds as a thiolate at the silver (Ag) crystal lattice leaving carboxylic-functional group open to bind with other chemicals as shown in Fig. 1(b). Next, separate solution of EDC $(75 \mathrm{mM})$ and NHS $(15 \mathrm{mM})$ is prepared and dropped $(100 \mu \mathrm{L})$ successively using a micropipette followed by incubation for 1 minute in tightly closed petri dish. This is followed by dropping polyvalent antivenom $\operatorname{IgG}(2 \mathrm{mg} / \mathrm{ml})$, and the chip is stored at $4{ }^{\circ} \mathrm{C}$ for $8 \mathrm{hrs}$. The free amine functional groups of EDC-NHS are blocked by dipping the chip in $50 \mathrm{mM}$ ethanolamine $(100 \mu \mathrm{L})$ solution for 10 minutes in order to avoid undesired linking of free amine group from EDC-NHS with the target analyte. Finally, the chip is gently washed with $0.5 \mathrm{~mL}$ phosphate buffer solution and stored at $4{ }^{\circ} \mathrm{C}$ for $12 \mathrm{hrs}$ before using them for SPR measurements.

\subsection{Elemental characterization method}

Spectroscopic measurements are performed in order to ensure the covalent attachment of antibody on the metal surface. The adsorption spectra of the samples before and after protein immobilization are recorded by an ultraviolet-visible spectroscopy (UV-Vis) optical absorption spectrometer (Shimadzu-2000). The absorbed light intensity is recorded from $200 \mathrm{~nm}$ to $800 \mathrm{~nm}$. The Fouriertransform infrared spectroscopy (Nicolet Impact 410) is performed to verify the chemical structure of the silver surface after the deposition of various layers.

\subsection{SPR measurement}

The optical measurements are performed using a custom-made portable SPR measurement setup based on Kretschmann's configuration [14]. A schematic representation of the experimental setup is shown in Fig. 2(a). Unlike the conventional SPR measurement system designed on Kretschmann's configurations which are likely to suffer from the bulky structure and complicated measurement process, the device demonstrated here is portable without the moving elements. It uses simple and inexpensive components that make labs with a limited budget to the custom-made SPR measurement setup for the quantitative and first-hand analysis of samples. A red light emitting diode (LED) of $635 \mathrm{~nm}$ wavelength is used as the light source. The diverging beams from the LED are passed through a polarizer to produce p-polarized light. The light beams are then directed through a right angle prism $(38 \mathrm{~mm} \times 38 \mathrm{~mm})$ with the high angular tolerance and flatness, to incident on the surface of Ag coated glass slide at different angles. The glass prism (BK7) and cover slip have closely matched refractive indices, and glycerine (1.42 RIU) is used as the optical glue for sticking cover slip on prism to avoid the presence of the air gap [29]. The reflected light from the sensor surface is made to converge using a convex lens with a focal length of $45 \mathrm{~mm}$ and collected using a universal serial bus (USB) interfaced charge-coupled device (CCD) camera. The lens and the camera are placed on an adjustable rail in order to focus the reflected light on the camera. The whole arrangements are housed inside an enclosure $(12 \mathrm{~mm} \times 12 \mathrm{~mm} \times 10 \mathrm{~mm})$ painted in black to minimize the interference with the measurement process. A flow cell [Fig. 2(b)] made of epoxy resin is pressed against the sensor surface, and the inlet/outlet connected to it is used to inject samples in/out of the chamber.

Prior to the venom protein binding studies, the phosphate buffer solution (PBS) (pH 7.4) is made to flow through the self-assembled monolayer (SAM) in order to establish a baseline reading. In subsequent steps, the sensor is exposed to different concentrations of crude cobra venom $(0.1 \mathrm{mg} / \mathrm{ml}$ to $1.0 \mathrm{mg} / \mathrm{ml})$ in the PBS solution for 12 minutes. This results association of proteins is present in the venom with polyvalent antivenom as depicted in Fig. 2(c). Finally, PBS is once again injected through the 
sensor surface to start the dissociation of protein with the ligands.

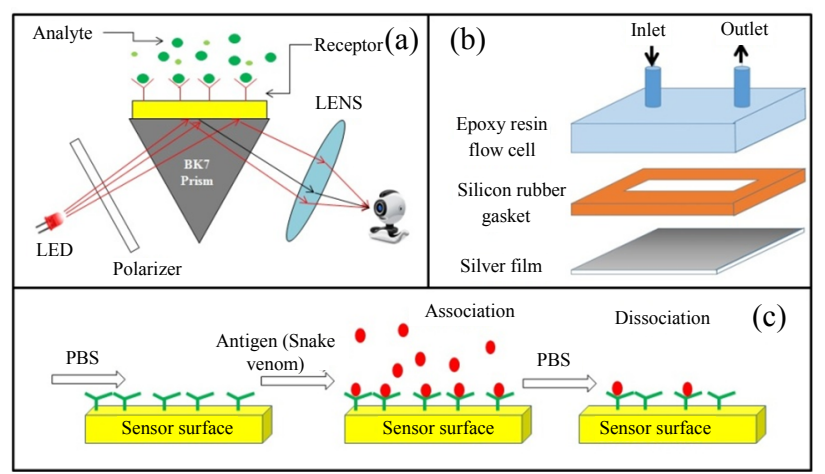

Fig. 2 Schematic representation of (a) the experimental setup, (b) flow cell, and (c) sensor measurement procedure.

\section{Results}

\subsection{Elemental and structural characterization}

Figure 3 presents the optical absorption spectra using the UV-Vis spectroscopy of the sensor surface before and after antibody immobilization along with that of the pure silver coated substrate. For pure silver, the absorbance peak is observed at $310 \mathrm{~nm}$, and the successive deposition of the overlying layer on the silver film results in a subsequent shift in the

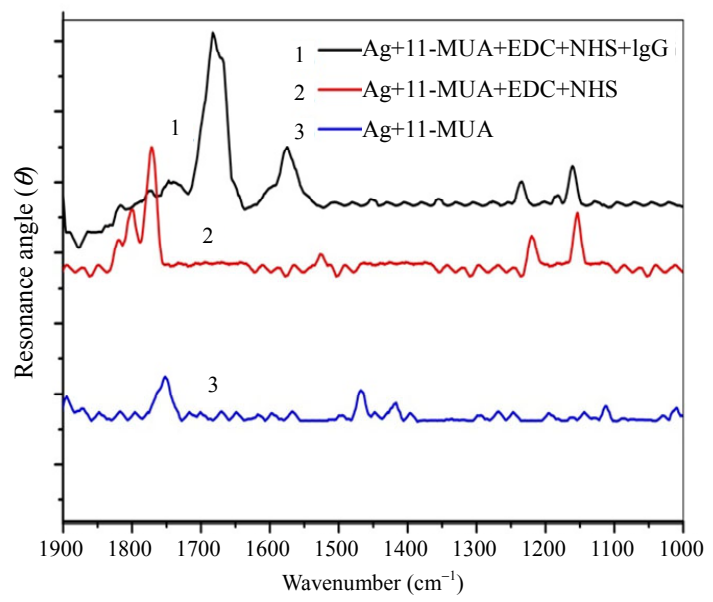

(a)
SPR dip. Functionalization with 11-MUA causes the absorption peak to red-shift by $\sim 5 \mathrm{~nm}$ which is due to the chemisorption of thiol molecules to the metal surface. Similar results were reported earlier by Aslan et al. [30]. Upon antibody conjugation, an absorbance peak further red-shifted by $15 \mathrm{~nm}$ indicates an increase in the local dielectric constant around metal surface molecules due to additional molecular layer [30, 31].

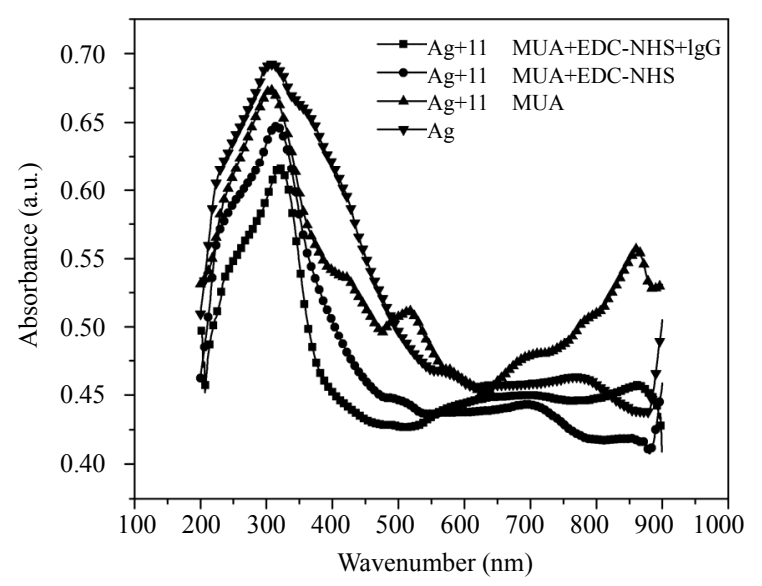

Fig. 3 UV-Vis spectra of the sensor surface before and after antibody immobilization.

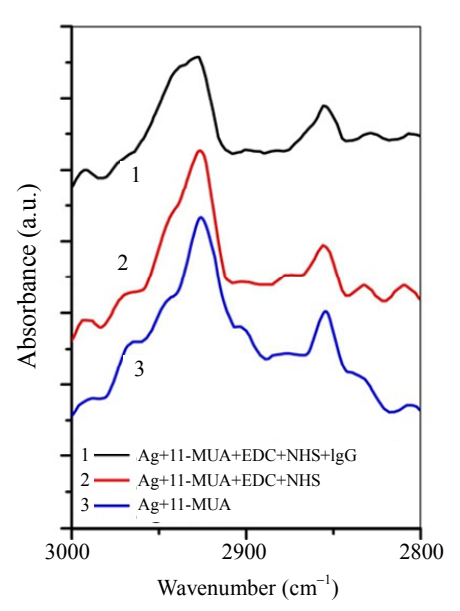

(b)

Fig. 4 FTIR spectra of the sensor surface before and after antibody immobilization.

Surface modifications at various layers are confirmed by the Fourier transform infrared spectroscopy (FTIR). Figure 4 displays the infrared spectroscopy (IR) spectrum of the sensor surface after the deposition of 11-MUA, activation with NHS-EDC, and antibody conjugation. The end group of 11-MUA is - $\mathrm{COOH}$. The amine group of NHS bind with this group via EDC finally converts into COO-NHS. After the immobilization of antibody, the end group is again converted into COO-N-IgG. Figure 4(a) shows the carbon band region in the IR spectra. This region is characterized 
by two absorbance peaks at wavenumbers $2932 \mathrm{~cm}^{-1}$ and $2856 \mathrm{~cm}^{-1}$ which occur due to $\mathrm{CH}_{2}$ asymmetric and symmetric stretches [32]. Figure 4(b) shows carboxyl and amide region in the IR spectra. As compared with the 11-MUA coated film, NHS terminated film display three characteristic bands around $1820 \mathrm{~cm}^{-1}, 1798 \mathrm{~cm}^{-1}$, and $1765 \mathrm{~cm}^{-1}$ which are responsible for stretch modes in COO-NHS ester. After IgG immobilization, new amide bands appear around $1570 \mathrm{~cm}^{-1}$ and $1687 \mathrm{~cm}^{-1}$ (amide I and amide II), indicating the existence of IgG on the surface [33].

\subsection{Device optimization}

In order to optimize the measurement using the custom-made setup, the standard sample of known

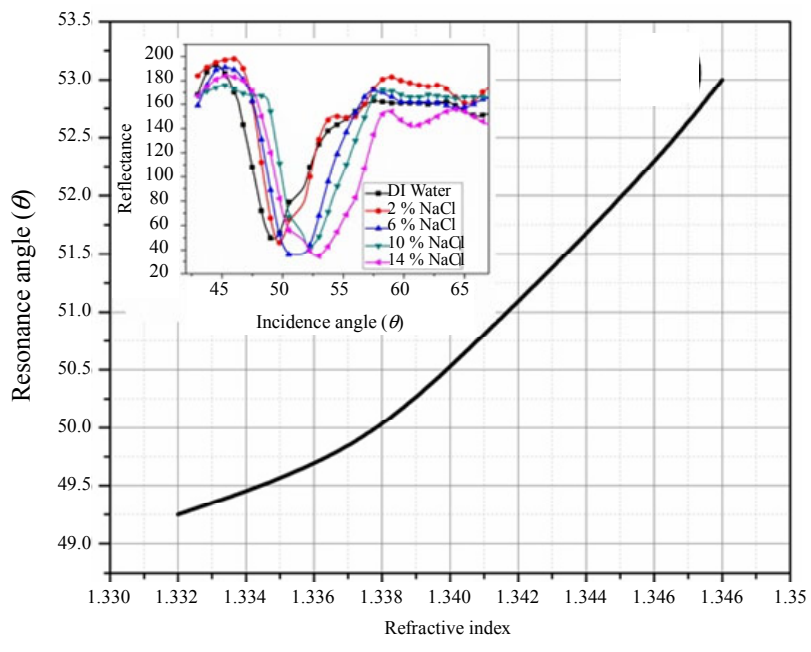

(a) refractive index is passed through the flow cell which is pressed against a glass slide coated with silver. The variation in the resonance angle due to the standard solution of sodium chloride and ethanol is plotted in Fig. 5, as a function of the change in the refractive index of the medium. In both, the measurement baseline is established by passing a stream of deionised (DI) water for which the resonance dip occurs at an incidence angle of $49^{\circ}$. For the measured range, both the tested samples produce similar characteristics of higher red shift in the resonance dip with an increase in the refractive index of the medium. The inset in the figure shows the raw data of the SPR measurement.

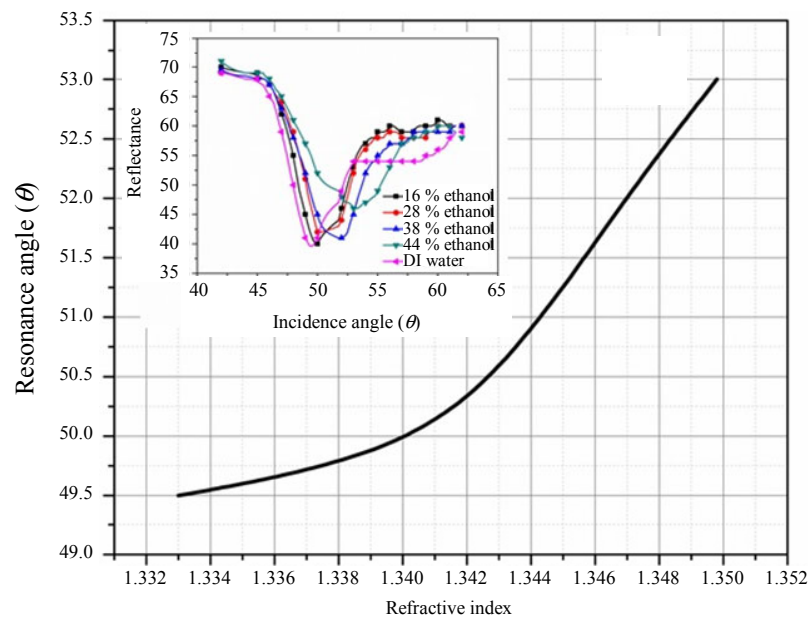

(b)

Fig. 5 Variation of SPR dip with refractive index using standard solution of sodium chloride (a) and ethanol (b).

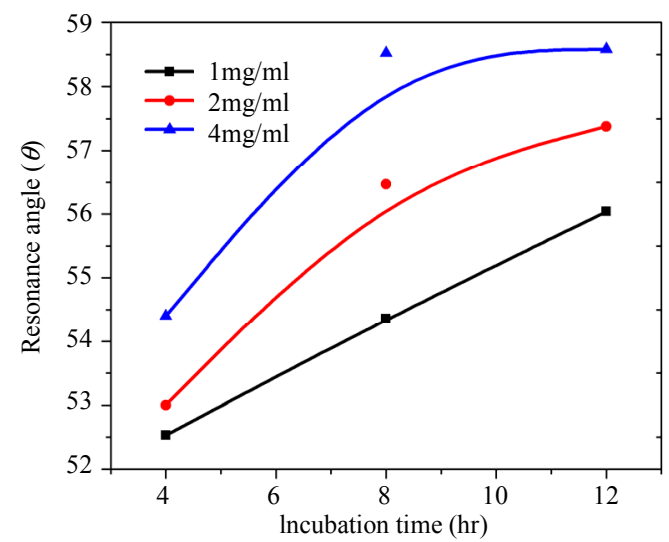

Fig. 6 Antibody immobilization optimization on the sensor surface.
The antigen-antibody interaction in the SPR sensor strongly depends on the proper immobilization of antibody on the sensor surface. A set of nine IgG immobilised sensors are fabricated by varying the concentrations of antibody $(1 \mathrm{mg} / \mathrm{ml}-4 \mathrm{mg} / \mathrm{ml})$ and incubation time $(4 \mathrm{hrs}-$ $12 \mathrm{hrs}$ ). The obtained results of SPR measurements (shown in Fig. 6) indicate a linear shift in the resonance dip with incubation time for the sensors constructed with $1 \mathrm{mg} / \mathrm{ml}$ antibody. However, for the sensor with higher antibody concentration $(2 \mathrm{mg} / \mathrm{ml}$ and $4 \mathrm{mg} / \mathrm{ml}$ ), the shift in the resonance dip seems to 
saturate after $8 \mathrm{hrs}$ of incubation. Henceforth, all sensors are constructed using antibody concentration of $2 \mathrm{mg} / \mathrm{ml}$ and an incubation time of $8 \mathrm{hrs}$.

\subsection{Sensor response}

Figure 7(a) plots the intensity of the reflected light from the sensor as a function of the incident angle. The subsequent red shift of the resonance dip with the addition of successive deposited layer on the sensor surface confirms the bonding between staked layers. In order to study the interaction, crude venoms with different concentrations are passed to flow through the IgG covered sensor surface. All measurements are conducted by exposing the sensor

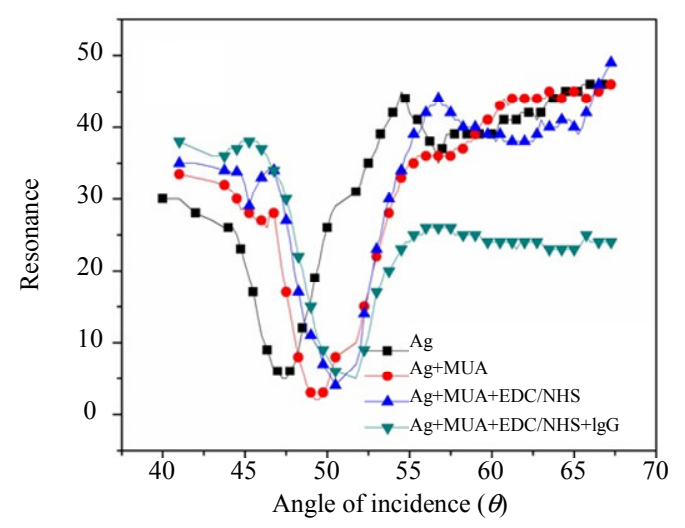

(a) to the venom protein in the PBS buffer solution for 12 minutes. The measured output data are plotted in Fig. 7(b), and as expected, the shift in the resonance dip is observed to increase from $54^{\circ}$ to $60^{\circ}$ when the concentration of the venom protein increases from $0.1 \mathrm{mg} / \mathrm{ml}$ to $1.0 \mathrm{mg} / \mathrm{ml}$. The change in the SPR angle is due to the change in the local refractive index near the sensor surface which confirms the presence of the conjugated material. The higher sensitivity at the higher concentration is obviously due to the higher change in the refractive index as a result of strong antigen-antibody interaction.

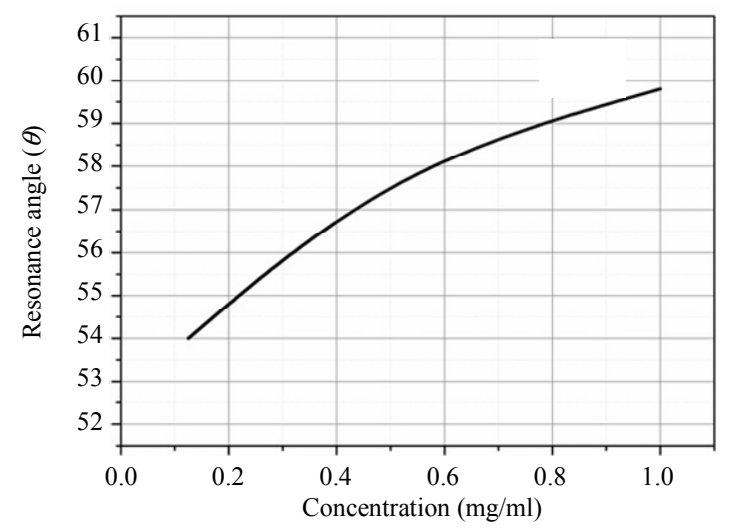

(b)

Fig. 7 SPR measurement: (a) staked layers and (b) response to venom protein.

The sensorgram of the protein detection with 15 minutes association followed by 10 minutes

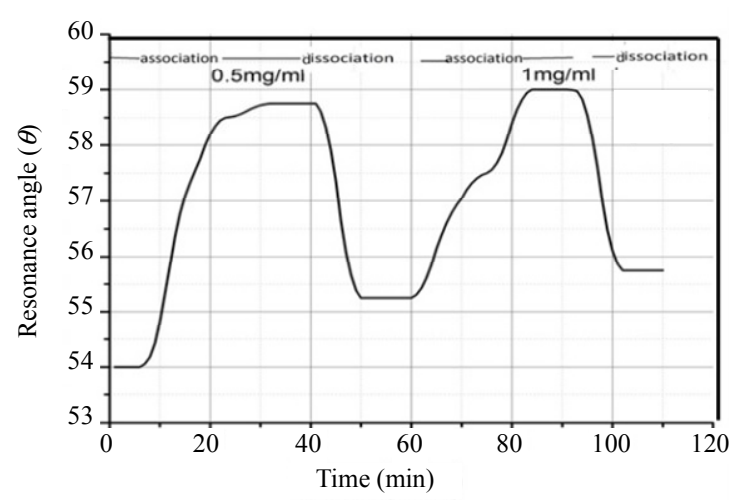

(a) dissociation is shown in Fig. 8(a). The baseline is initially set by flowing PBS through the IgG

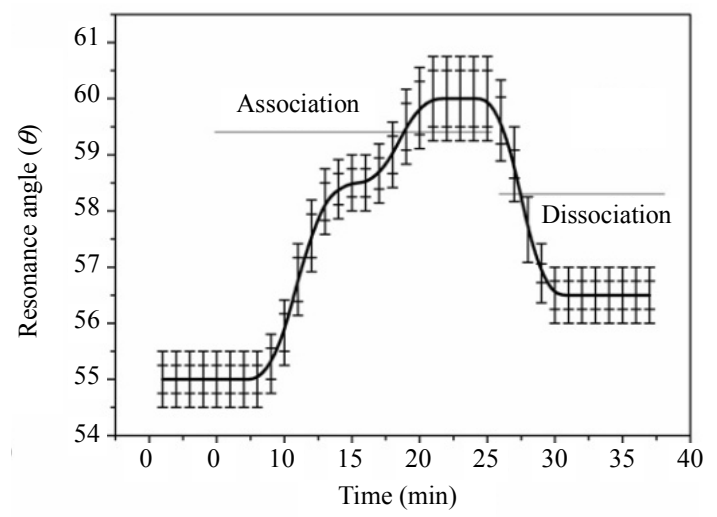

(b)

Fig. 8 SPR sensorgrams showing binding kinetic using venom proteins with different concentrations: (a) repeatability test and (b) under the same measurement condition using the analyte concentration of $1 \mathrm{mg} / \mathrm{ml}$. 
functionalized sensor surface for 10 minutes. The sensor signal reaches a maximum on passing crude venom when the sensor is said to be in the association phase. The sensor signal tends to return to the baseline when protein injection is stopped during the dissociation process. Although the signal does not return completely to its baseline, it reaches to a very close value. The reliability of the sensor is also investigated by exposing a sensor 3 times subsequently to a fixed concentration of the analyte under the identical measurement conditions. The measured data reveal a good repeatable behavior of the sensors as shown in Fig. 8(b).

\subsection{Discussion}

Commercially, available systems based on the SPR technique for investigating binding interaction are highly sophisticated in nature but available at the high cost. In this paper, we report a simple and inexpensive technique for protein detection based on studying antigen-antibody interaction. Other methods like mass spectroscopy and ELISA are limited by the complicated sample preparation, long analysis time, expensive and large instrumentation, involvement of antibody labelling, etc. However, in the whole experimental process, polyvalent antivenom $\operatorname{IgG}$ is used to study its interaction with the crude venom of Indian cobra. Sequencing analysis has revealed a highly complex proteome structure of venom containing proteins from many protein families [20]. A detailed investigation into individual purified protein present in snake venom against specific monoclonal antivenom is therefore necessary that may produce a unique pattern. The unique pattern generated from an unknown sample is expected to unfold the significant information about the identification of the snake. Further work is also necessary to assess the contribution of individual protein in the toxicity of the venom which is out of scope of the present research. Also, all the measurements reported here are performed in the standard PBS buffer solution, and the effect of the presence of other blood ingredients is ignored.

\section{Conclusions}

In this paper, we demonstrate the detection of snake venom protein derived from Indian cobra using a custom-made portable instrument based on the surface plasmon resonance technique. NHS-EDC activated thiolate silver substrate is used to immobilize the antibody which acts as the sensing element. Surface modification due to the deposition of various layers is examined by spectroscopic measurements which confirm the existence of properly immobilized antibody along with various other deposited layers. The interaction of the venom protein with IgG is investigated by flowing crude venom over the sensor surface in the concentration range of $0.10 \mathrm{mg} / \mathrm{ml}-1.0 \mathrm{mg} / \mathrm{ml}$. A red shift in the resonance dip as high as $5^{\circ}-6^{\circ}$ is observed due to the antigen-antibody interaction. The measured data reveal the highly repeatable behavior of the fabricated sensors.

Open Access This article is distributed under the terms of the Creative Commons Attribution 4.0 International License (http://creativecommons.org/licenses/by/4.0/), which permits unrestricted use, distribution, and reproduction in any medium, provided you give appropriate credit to the original author(s) and the source, provide a link to the Creative Commons license, and indicate if changes were made.

\section{References}

[1] P. R. Edwards, A. Gill, D. V. Pollard-Knight, M. Hoare, P. E. Buckle, P. A. Lowe, et al., "Kinetics of protein-protein interactions at the surface of an optical biosensor," Analytical Biochemistry, 1995, 231(1): 210-217.

[2] T. Endo, K. Kerman, N. Nagatani, Y. Takamura, and E. Tamiya, "Label-free detection of peptide nucleic acid-DNA hybridization using localized surface plasmon resonance based optical biosensor," Analytical Chemistry, 2005, 77(21): 6976-6984.

[3] J. Homola, "Present and future of surface plasmon resonance biosensors," Analytical and Bioanalytical Chemistry, 2003, 377(3), 528-539.

[4] H. Lijie, P. Quentin, L. Iban, Y. S. Aritz, P. Amaia, Z. Amaia, et al., "Label-free femtomolar cancer 
biomarker detection in human serum using grapheme coated surface plasmon resonance chip," Biosensors and Bioelectronics, 2017, 89(1): 606-611.

[5] E. Mauriz, A. Calle, J. J. Manclús, A. Montoya, and L. M. Lechuga. "Multi-analyte SPR immunoassays for environmental biosensing of pesticides," Analytical \& Bioanalytical Chemistry, 2007, 387(4): 1449-1458.

[6] Y. Li, X. Liu, and Z. Lin, "Recent developments and applications of surface plasmon resonance biosensors for the detection of mycotoxins in foodstuffs," Food Chemistry, 2012, 132(3): 1549-1554.

[7] H. R. Sim, A. W. Wark, and H. J. Lee, “Attomolar detection of protein biomarkers using biofunctionalized gold nanorods with surface plasmon resonance," Analyst, 2010, 135(10): 2528-2532.

[8] Y. Wang, W. Knoll, and J. Dostalek, "Bacterial pathogen surface plasmon resonance biosensor advanced by long range surface plasmons and magnetic nanoparticle assays," Analytical Chemistry, 2012, 84(19): 8345-8350.

[9] J. Homola, "Surface plasmon resonance sensors for detection of chemical and biological species," Chemical Reviews, 2008, 108: 462-493.

[10] K. Yokoyama, M. Oishi, and M. Oshima, "Development of an enhanced surface plasmon resonance sensor substrate by investigating a periodic nanohole array configuration," Journal of Applied Physics, 2015, 118(2): 023101-1-023101-7.

[11] R. Boruah, D. Mohanta, A Choudhury, P. Nath, and G. A. Ahmed, "Surface plasmon resonance-based protein bio-sening using a Krestschmann configured double prism arrangement," IEEE Sensors Journal, 2015, 15: 6791-6796.

[12] Y. W. Fen, W. M. M. Yunus, Z. A. Talib, and N. A. Yusof, "Development of surface plasmon resonance sensor for determining zinc ion using novel active nanolayers as probe," Spectrochemica Acta Part A: Molecular and Biomolecular Spectroscopy, 2015, 134: 48-52.

[13] D. G. Hong, T. W. Kim, K. B. Kim, J. S. Yuk, and K. S. Ha, "Development of an immunosensor with angular interrogation-based SPR spectroscopy," Measurement Science \& Technology, 2007, 18(5): 1367-1371.

[14] E. Kretschmann and H. Reather, "Radiative decay of non-radiative surface plasmons excited by light," Zeitschrift für Naturforschung, 1968, 23: 2135-2136.

[15] A. Otto, "Excitation of nonradiative surface plasma waves in silver by the method of frustrated total reflection," Zeitschrift Für Physik, 1968, 216(4): 398-410.

[16] R. A. Harrison, A. Hargreaves, S. C. Wagstaff,
B. Faragher, and D. G. Lalloo, "Snakebite envenoming: a disease of poverty," PLoS Neglected Tropical Diseases, 2009, 3(12): 1-6.

[17] J. J. Calvete, P. Juárez, and L. Sanz, "Snake venomics: strategy and applications," Journal of Mass Spectrometry, 2010, 42(11): 1405-1414.

[18] L. V. Dong, K. H. Eng, L. K. Quyen, and P. Gopalakrishnakone, "Optical immunoassay for snake venom detection," Biosensors and Bioelectronics, 2004, 19(10): 1285-1294.

[19] G. D. Brand, R. Salbo, T. J. Jørgensen, C. Jr. Bloch, E. E. Boeri, C. V. Robinson, et al., "The interaction of the antitoxin DM43 with a snake venom metalloproteinase analyzed by mass spectrometry and surface plasmon resonance," Journal of Mass Spectrometry, 2012, 47(5): 567-573.

[20] I. Malih, M. R. A. Rusmili, T. Y. Tee, Rachid Saile, Noreddine Ghalim, and Iekhsan Othman, "Proteomic analysis of Moroccan cobra naja haje legionis venom using tandem mass spectrometry," Journal of Proteomics, 2014, 96(2): 240-252.

[21] H. J Simon, D. E Mitchell, and J. G Watson, "Surface plasmons in silver films - a novel undergraduate experiment," American Journal of Physics, 1975, 43(7): 630-636.

[22] S. Szunerits, X. Castel, and R. Boukherroub, "Surface plasmon resonance investigation of silver and gold films coated with thin indium tin oxide layers: influence on stability and sensitivity," Journal of Physics Chemistry C, 2008, 112: 15813-15817.

[23] X. C. Yuan, B. H. Ong, Y. G. Tan, D. W. Zhang, R. Irawan, and S. C. Tjin, "Sensitivitystability-optimized surface plasmon resonance sensing with double metal layers," Journal of Optics A Pure \& Applied Optics, 2006, 8(11): 959-963.

[24] S. B. Nimse, K. Song, M. D. Sonawane, D. R. Sayyed, and T. Kim, "Immobilization techniques for microarray: challenges and applications," Sensors, 2014, 14(12): 22208-22229.

[25] F. Rusmini, Z. Zhong, and J. Feijen, "Protein immobilization strategies for protein biochis," Biomacromolecules, 2007, 8(6): 1775-1789.

[26] J. E. Lee, J. H. Seo, C. S. Kim, Y. Kwon, J. H. Ha, S. S. Choi, et al., "A comparative study on antibody immobilization strategies onto solid surface," Korean Journal of Chemical Engineering, 2013, 30(10): 1934-1938.

[27] C. D. Hodneland, Y. S. Lee, D. H. Min, and M. Mrksich, "Selective immobilization of proteins to self-assembled monolayers presenting active site-directed capture ligands," Proceedings of the National Academy of Sciences, 2002, 99(8): 5048-5052. 
[28] R. F. Peters, L. Gutierrez-Rivera, S. K. Dew, and M. Stepanova, "Surface enhanced Raman spectroscopy detection of biomolecules using EBL fabricated nanostructured substrates," Journal of Visualized Experiments Jove, 2015, 2015(97): e52712-1-e52712-17.

[29] L. F. Hoyt, "New table of the refractive index of pure glycerol at $20{ }^{\circ} \mathrm{C}$," Industrial \& Engineering Chemistry, 1934, 26(3): 329-332.

[30] K. Aslan, C. C. Luhrs, and V. H. Pérez-Luna, "Controlled and reversible aggregation of biotinylated gold nanoparticles with streptavidin," Journal of Physical Chemistry B, 2004, 108(40): 15631-15639.

[31] G. Weng, J. Li, and J. Zhoa, "Enhanced resonance light scattering of antibody covalently conjugated gold nanoparticles due to antigen-antibody interaction induced aggregation," Nanoscience and Nanotechnology Letters, 2013, 5(8): 1-7.

[32] B. M. Amoli, S. Gumfekar, A. Hu, Y. N. Zhou, and B. Zhao, "Thiocarboxylate functionalization of silver nanoparticles: effect of chain length on the electrical conductivity of nanoparticles and their polymer composites," Journal of Materials Chemistry, 2012, 22(37): 20048-20056.

[33] E. Goormaghtigh, J. M. Ruysschaert, and V. Raussens, "Evaluation of the information content in infrared spectra for protein secondary structure determination," Biophysical Journal, 2006, 90(8): 2946-2957. 